\title{
Analysis of clinical effects and mechanism of recombinant human interleukin-11 with glucocorticoids for treatment of idiopathic thrombocytopenic purpura
}

\author{
XIFENG WU ${ }^{1}$, LIJUAN WANG $^{1}$, LIN SUN $^{1}$, TANTAN LI $^{1}$ and XUEHONG RAN ${ }^{2}$ \\ ${ }^{1}$ Department of Hematology, Laiwu City People's Hospital, Laiwu, Shandong 271100; \\ ${ }^{2}$ Department of Hematology, Weifang People's Hospital, Weifang, Shandong 261041, P.R. China
}

Received June 21, 2016; Accepted December 19, 2016

DOI: $10.3892 /$ etm.2016.3989

\begin{abstract}
The aim of the present study was to evaluate the effectiveness and safety of recombinant human interleukin-11 (IL-11) with glucocorticoids for treatment of adult idiopathic thrombocytopenic purpura (ITP) and the regulatory effect on immune mechanisms. A total of 80 patients with initial diagnosis of ITP admitted to our hospital were selected. Patients were randomly divided into the control group and observation group, with 40 cases each. The control group received glucocorticoids treatment, and the observation group received IL-11 and glucocorticoids. The treatment effects were compared. The total effective rate and effective degree of the observation group was higher than in the control group and the difference was statistically significant $(\mathrm{P}<0.05)$; comparing the incidence of complications of the two groups, there was no statistical difference $(\mathrm{P}>0.05)$. In the observation group, onset time was reduced, platelet recovery level increased and platelet antibody positive rate decreased, and the differences were statistically significant $(\mathrm{P}<0.05)$. The total treatment course was shorter and recurrence rate was lower in the observation group compared with the control group, and the differences were statistically significant $(\mathrm{P}<0.05)$. The percentage of $\mathrm{CD} 4{ }^{+} \mathrm{CD} 25^{+}$regulatory $\mathrm{T}$ cells decreased in the two groups after treatment, and was more pronounced in the observation group. The difference was statistically significant $(\mathrm{P}<0.05)$. In conclusion, IL-11 with glucocorticoids for the treatment of adult ITP is safe and effective, and may be associated with decreased percentage of $\mathrm{CD} 4{ }^{+} \mathrm{CD} 25^{+}$regulatory $\mathrm{T}$ cells.
\end{abstract}

Correspondence to: Dr Xuehong Ran, Department of Hematology, Weifang People's Hospital, 151 Guangwen Street, Weifang, Shandong 261041, P.R. China

E-mail: xue_hong1212@163.com

Key words: interleukin-11, glucocorticoids, idiopathic thrombocytopenic purpura, $\mathrm{CD} 4^{+} \mathrm{CD} 25^{+}$regulatory $\mathrm{T}$ cells

\section{Introduction}

Idiopathic thrombocytopenic purpura (ITP) is an acquired immune-mediated hemorrhagic disease. Highly expressed anti-platelet autoantibodies in circulation bind epitopes on platelet membrane glycoprotein GpIIb/III or GpIb/IX, which causes platelet depletion. The initial symptom is primarily bleeding. On hemogram, there is decreased single platelet count, with normal white blood cell count and hemoglobin level. Myelography indicates increased megakaryocyte counts or dysmaturity. Pediatric cases are mostly acute onset, and adult cases are mostly chronic. The incidence in the pediatric population is approximately $0.5 / 1$ million (1). The specific pathogenic mechanism is not yet clear, and glucocorticoids are the preferred drugs for the treatment of ITP. Moreover, immunoglobulin therapy, splenectomy, splenic embolization, immunosuppression and traditional Chinese medicine are optional methods (2). The overall effective treatment rate is $75-85 \%$, with a recurrence rate of $20-35 \%$ (3). Clinical treatment is classified as three types; initial treatment, retreatment, and the intractable stage. Patients undergoing retreatment and with intractability often require a combination of treatments. With extended treatment course, clinical effect decreases and the rates of adverse drug reactions increase (4).

According to recent findings (5), the secondary B-cell activation barrier following $\mathrm{T}$ cell-mediated immune disorders may be the true cause of ITP. $\mathrm{CD} 4{ }^{+} \mathrm{CD} 25^{+}$regulatory $\mathrm{T}$ cells and interleukin-11 (IL-11) were effective in promoting the recovery of platelet count and function (6). Recombinant human IL-11 had a biological effect, which could directly play a role in stimulating megakaryocyte and hematopoietic stem cell proliferation, differentiation and maturation; promoting platelet production; increasing peripheral platelet count; maintaining platelet function; and promoting platelet production (7).

The present study was designed to analyze the effectiveness and safety of IL-11 with glucocorticoids for the treatment of adult ITP and the regulatory effect on T cells.

\section{Patients and methods}

Patients. Eighty patients with ITP who were diagnosed in Laiwu City People's Hospital for the first time from 
January 2013 to June 2015 were selected. Their symptoms included skin purpura, nasal bleeding, gingival bleeding, hematemesis, and black stool (4). The patients were diagnosed via routine blood examination, blood smear, bone marrow biopsy, blood antibody tests, splenic function tests, as well as imaging examinations. The inclusion criteria for the study were: i) Conformed to the ITP diagnostic criteria and underwent treatment for the first time; ii) effective response to glucocorticoid treatment; and iii) completed the course of treatment. The exclusion criteria included: i) Other types of purpura such as platelet dysfunction purpura, allergic purpura, leukemia purpura and hematologic abnormalities caused by other clear external factors; ii) severe bleeding tendency that could not be corrected; and iii) poor compliance, simultaneous participation in another study, or incomplete medical history.

The control and observation groups had 40 patients each and were divided based on the parity digit method, according to admission order. There were 20 males and 20 females in the control group, aged from 20 to 53 years with an average age of $42.2 \pm 13.6$ years; the course of disease was 5-20 days with an average course of $12.3 \pm 5.5$ day; platelet count was $10-40 \times 10^{9} / 1$ with an average count of $22.5 \pm 10.3 \times 10^{9} / 1$; and 32 cases were positive for anti-platelet antibodies and eight were negative. There were 22 males and 18 females in the observation group, aged from 23 to 55 years with an average age of $43.8 \pm 13.8$ years; the course of disease was 3-22 days with an average course of $12.5 \pm 6.2$ days; and the platelet count was $12-36 \times 10^{9} / 1$ with an average count of $22.2 \pm 13.5 \times 10^{9} / 1$. Thirty-three cases were positive for anti-platelet antibodies and seven were negative. Baseline data of the two groups were comparable.

Treatment methods. Patients in the two groups received symptomatic treatment including hemostatic drugs, nutritional support, and infusion of concentrated platelets and other blood products when necessary. The control group received glucocorticoids, immunoglobulin, cytotoxic drugs, traditional Chinese medicine and other treatments. Specific schemes were: Intravenous infusion of methylprednisolone $(1.0 \mathrm{~g} /$ day for 3 days); and oral prednisone was given on the 4th day at a dose of $1 \mathrm{mg} / \mathrm{kg} /$ day. Platelet counts were monitored, and when platelets increased to normal levels, the dose was gradually decreased by $5 \mathrm{mg} /$ week. When platelet levels were stabilized, the treatment was maintained for 3 to 6 months at a dose of $5-10 \mathrm{mg} /$ days.

The observation group received IL-11 treatment combined with glucocorticoids. In the early stage of treatment with intravenous infusion of methylprednisolone, subcutaneous injections of IL-11 were simultaneously given at a dose of $25-50 \mu \mathrm{g} / \mathrm{kg} /$ day for 7 days. Dosage regimens of methylprednisolone were the same as above. If there were severe complications during treatment, drug treatment was stopped and observation with symptomatic treatment was provided.

Observational indexes and evaluation of curative effect. Clinical symptoms, platelet parameters, and bone marrow megakaryocytes were evaluated to assess curative effect. Clinical symptoms included fatigue, weakness, chest tightness, shortness of breath, dizziness, paleness in the face, and degree of skin bleeding. Platelet parameters included total platelet count, platelet volume, platelet contraction time, and platelet antibody and complement levels. Bone marrow smear (area, $3 \times 1.5 \mathrm{~cm}$ ) was used to detect the quantity of giant cells and to calculate the number of cells per unit area. Evaluation of results was in accordance with the ITP curative effect standards formulated by the National Conference on Hematology. According to these standards, marked effectiveness implied that symptoms disappeared, there was no recurrence for three months, and platelet count and number of bone marrow megakaryocytes returned to normal levels. Effectiveness implied that symptoms improved significantly, platelet count increased up to $>30 \times 10^{9} / 1$, or absolute count $>50 \times 10^{9} / 1$, and the bone marrow megakaryocyte number improved significantly. Ineffectiveness suggested that the symptoms had no improvement or were aggravated, platelet count was $\leq 50 \times 10^{9} / 1$, and the number of bone marrow megakaryocytes did not improve or were aggravated.

Safety indexes included routine examinations of blood, urine and stool; electrocardiogram; liver and kidney function tests; adverse drug responses and complications, which included disability, severe hemorrhage, aggravated nerve and cognitive events, bone marrow and digestive tract abnormalities, and death.

Onset time, platelet recovery level, positive rate of anti-platelet antibodies, total treatment course, recurrence after treatment and peripheral $\mathrm{CD} 4{ }^{+} \mathrm{CD} 25^{+}$regulatory T-cell ratio before and after treatment were compared. $\mathrm{CD} 4^{+} \mathrm{CD} 25^{+}$ regulatory T-cell count was assessed by FACSCaliber flow cytometry (BD Biosciences, Franklin Lakes, NJ, USA). Rabbit monoclonal FITC-labeled anti-human CD4 antibody (cat. no. F1773), mouse monoclonal PE-labeled anti-human CD25 monoclonal antibody (cat. no. SAB4700364), rabbit monoclonal antibody FITC negative control (cat. no. SAB5500149), and rabbit monoclonal anti-mouse PE-IgG1 antibody (cat. no. SAB3701171), FITC-labeled anti-human CD4 monoclonal antibody, PE-labeled CD25 monoclonal antibody, FITC negative control, and PE-mouse IgG1 were all from Sigma-Aldrich (St. Louis, MO, USA). The main experimental steps were as follows: Two individually labelled flow tubes were used. Heparin anticoagulated whole blood (100 $\mu \mathrm{l})$ was added to the bottom of each tube. Then, $20 \mu \mathrm{l}$ PE-mouse IgG1 and anti-CD4, anti-CD25 were added in this order to the tube. The mixtures were left to stand for $20 \mathrm{~min}$ in the dark. Subsequently, $2 \mathrm{ml}$ of 1:10 dilution of $1 \mathrm{X}$ red blood cell lysing solution was added, and incubated for $10 \mathrm{~min}$ in the dark after mixing. The liquid was centrifuged at a speed of $300 \mathrm{x} \mathrm{g}$ for $5 \mathrm{~min}$ after liquid in the tube became transparent, and the supernatant was discarded. Following this, $2 \mathrm{ml}$ of phosphate-buffered saline (PBS) was added to each tube, $300 \mathrm{x}$ g was centrifuged for 5 min after mixing, and the supernatant was discarded. After centrifugation, $0.5 \mathrm{ml}$ PBS was added, followed by mixing. Samples were analyzed after a 1-h incubation at $4^{\circ} \mathrm{C}$.

Statistical analysis. SPSS 19.0 software (Chicago, IL, USA) was used for data analysis. Quantitative data are presented as mean \pm standard deviation. Comparison between groups was made using one-way ANOVA followed by a post-hoc test [least significant difference (LSD)]. Countable data are presented as rate, and comparisons within groups were corrected by the $\chi^{2}$ test. Ranked data were tested by the rank sum test. $P<0.05$ was considered to indicate a statistically significant difference. 
Table I. Comparison of effective rate and complication occurrence rate [case (\%)].

\begin{tabular}{|c|c|c|c|c|c|c|c|c|c|c|}
\hline Groups & Case & $\begin{array}{c}\text { Marked } \\
\text { effectiveness }\end{array}$ & Effectiveness & Ineffectiveness & $\begin{array}{l}\text { Effective } \\
\text { rate }\end{array}$ & $\begin{array}{c}\text { Bleeding } \\
\text { event }\end{array}$ & $\begin{array}{l}\text { Liver and } \\
\text { kidney } \\
\text { dysfunction }\end{array}$ & $\begin{array}{c}\text { Bone marrow and } \\
\text { digestive tract } \\
\text { abnormalities }\end{array}$ & Death & $\begin{array}{c}\text { Occurrence } \\
\text { rate of } \\
\text { complications }\end{array}$ \\
\hline Control & 40 & 7 (17.5) & $16(40.0)$ & $17(42.5)$ & $23(57.5)$ & 1 & 1 & 1 & 1 & $4(10.0)$ \\
\hline Observation & 40 & $15(37.5)$ & $17(42.5)$ & $8(20.0)$ & $32(80.0)$ & 1 & 2 & 1 & 1 & $5(12.5)$ \\
\hline$\chi^{2}$ & & & 6.179 & & & & 4.713 & & & 0.000 \\
\hline $\mathrm{P}$-value & & & 0.046 & & & & 0.030 & & & 1.000 \\
\hline
\end{tabular}

Table II. Comparison of onset time, platelet recovery level, platelet antibody positive rate.

\begin{tabular}{lcccc}
\hline Groups & Case & $\begin{array}{c}\text { Onset } \\
\text { time } \\
\text { (days) }\end{array}$ & $\begin{array}{c}\text { Platelet } \\
\text { recovery } \\
\text { level }\left(\mathrm{x} 10^{9} / 1\right)\end{array}$ & $\begin{array}{c}\text { Platelet antibody } \\
\text { positive rate } \\
\text { [case }(\%)]\end{array}$ \\
\hline Control & 40 & $4.2 \pm 0.6$ & $78.5 \pm 14.2$ & $11(27.5)$ \\
Observation & 40 & $3.5 \pm 0.7$ & $92.6 \pm 13.5$ & $4(10.0)$ \\
$\mathrm{t}\left(\chi^{2}\right)$ & & 5.632 & 5.867 & 4.021 \\
P-value & & 0.034 & 0.030 & 0.045 \\
\hline
\end{tabular}

Table III. Comparison of total treatment course and recurrence rate.

\begin{tabular}{lccc}
\hline Groups & Case & $\begin{array}{c}\text { Total treatment } \\
\text { course (months) }\end{array}$ & $\begin{array}{c}\text { Recurrence rate } \\
{[\text { case }(\%)]}\end{array}$ \\
\hline Control & 40 & $1.9 \pm 0.5$ & $12(30.0)$ \\
Observation & 40 & $1.5 \pm 0.3$ & $6(15.0)$ \\
$\mathrm{t}\left(\chi^{2}\right)$ & & 5.327 & 4.500 \\
P-value & & 0.036 & 0.034 \\
\hline
\end{tabular}

\section{Results}

Comparison of the effective and the complication occurrence rates. The total effective rate and effective degree of the observation group were higher than those of the control group, and the differences were statistically significant $(\mathrm{P}<0.05)$. There was no difference in the comparison of complication occurrence rate between the two groups (P>0.05) (Table I).

Comparison of onset time, platelet recovery level, and platelet antibody positive rate. Compared to the control group, onset time was reduced in the observation group. Additionally, in the observation group, platelet recovery level increased and platelet antibody positive rate decreased, and the differences were statistically significant $(\mathrm{P}<0.05)$ (Table II).

Comparison of total treatment course and recurrence rate. Total treatment course and recurrence rate of the observation group were lower than those of the control group, and the differences were statistically significant $(\mathrm{P}<0.05)$ (Table III).
Table IV. Comparison of peripheral blood $\mathrm{CD} 4{ }^{+} \mathrm{CD} 25^{+}$regulatory $\mathrm{T}$ cell ratio $(\%)$.

\begin{tabular}{lcccr}
\hline Groups & $\begin{array}{c}\text { Before } \\
\text { treatment }\end{array}$ & $\begin{array}{c}\text { After } \\
\text { treatment }\end{array}$ & $\mathrm{t}$ & P-value \\
\hline Control & $23.6 \pm 5.8$ & $18.3 \pm 4.2$ & 5.426 & 0.030 \\
Observation & $24.2 \pm 5.3$ & $12.5 \pm 4.3$ & 5.867 & 0.025 \\
$\mathrm{t}$ & 0.238 & 6.426 & & \\
P-value & 0.867 & 0.012 & & \\
\hline
\end{tabular}

Comparison of ratio of peripheral blood $C D 4^{+} \mathrm{CD} 25^{+}$regulatory $T$ cells. Comparing the ratio of $\mathrm{CD} 4^{+} \mathrm{CD} 25^{+}$regulatory $\mathrm{T}$ cells of the two groups before treatment, the difference was not statistically significant $(\mathrm{P}>0.05)$. The ratio of $\mathrm{CD} 4{ }^{+} \mathrm{CD} 25^{+}$ regulatory $\mathrm{T}$ cells in the two groups decreased significantly after treatment and was more obvious in the observation group $(\mathrm{P}<0.05)$ (Table IV).

\section{Discussion}

A number of studies suggest that ITP is related to decreased immunity, occurrence of infection, spleen function and genetic factors. The relevant pathomechanisms include: i) The production of autoantibodies (8). ITP is characterized by antiplatelet autoantibodies. The antibodies combine with autoantigens to form compounds. Megakaryocytes cause serious damage to the compounds and reduce the number of platelets; ii) immune tolerance (9). Autoimmune tolerance is blocked, and platelet membrane glycoprotein antigens are frequently dysregulated, which further reduces the number of platelets, causing ITP; iii) B cell activating factor (10). This protein is involved in the pathophysiological process of a variety of diseases such as cancer. Increased B cell activating factor causes decreased levels of platelet autoantibodies, which accelerates the blood platelet defect; iv) bone marrow megakaryocyte abnormity (11). Decreased amount of megakaryocytes affects normal platelet production, which is a major cause of several diseases; and v) Th1/Th2 dysfunction (12). When the Th1/ Th2 ratio increases, IL-4/IL-10 production is decreased and platelets are phagocytosed, causing ITP.

For ITP, glucocorticoids are chosen as the primary method of treatment. Glucocorticoids inhibit the production of platelet antibodies, reduce the destructive effect of mononuclear cells/macrophages on platelets, and reduce capillary permeability. Platelet count in patients with acute ITP is below 
$20 \times 10^{9} / 1$, accompanied by severe hemorrhagic manifestations. High doses of corticosteroids and gamma globulin therapy are provided in most cases. The platelet count in patients with chronic ITP is between $20-50 \times 10^{9} / 1$, with mild or no hemorrhagic manifestations. Therapy may include splenectomy, platelet growth factors, vincristine, rituximab, and low dose glucocorticoids combined with IL-11. Approximately $60-80 \%$ of patients with ITP showed significant alleviation of symptoms after medication, but only $30 \%$ on long-term medication had a persistent effect. Disease progression may occur in $10-20 \%$ of patients with long-term alleviated disease (13). Hormone therapy for improvement of platelet production requires considerable time and cannot ensure effective control of disease over an extended period. This is liable to cause occurrence of adverse systemic reactions such as femoral head necrosis, metabolic syndrome, and even death (14). When the dose of glucocorticoids is too high or if it is ineffective after a prolonged period, combined therapy or another treatment strategy will be considered.

IL-11 may have important roles in vitro and in vivo, including as in vitro cell factor to effectively stimulate CD34 ${ }^{+}$ cell differentiation into megakaryocytes and produce functional platelets. It can induce the in vivo proliferation and differentiation of megakaryocytes, promote platelet production and maturity, inhibit the decrease of platelet number after bone marrow suppression, and reduce platelet infusion rate (15). The common adverse reactions mainly include acute fever, diarrhea, fatigue and malaise. Mild symptoms can be gradually alleviated following the adjustment of dose amount and rate (20-45 $\mu \mathrm{g} / \mathrm{kg} /$ day) (7).

The total effective rate and effective degree of the observation group was higher than in the control group and there was no difference in the occurrence of complications. The onset time of the observation group decreased, platelet recovery level increased, and platelet antibody positive rate decreased. The total treatment course was shorter and the recurrence rate was lower compared with the control group. The percentage of $\mathrm{CD} 4{ }^{+} \mathrm{CD} 25^{+}$regulatory $\mathrm{T}$ cells decreased in both groups after treatment, and was more pronounced in the observation group. The main functions of $\mathrm{CD} 4{ }^{+} \mathrm{CD} 25^{+}$regulatory $\mathrm{T}$ cells are immune regulation, immune suppression, and reducing $\mathrm{T}$ cell activation and proliferation by direct interaction. Furthermore, they play an important role in the pathogenesis of a variety of autoimmune diseases (16). Studies on the biological effects of IL-11 have shown that it plays a role in the inhibition of inflammatory response through activation of MAP and NF- $\kappa B$ (17).

In conclusion, IL-11 with glucocorticoids for treatment of adult ITP was safe and effective and may have been related to lowered percentage of $\mathrm{CD} 4{ }^{+} \mathrm{CD} 25^{+}$regulatory $\mathrm{T}$ cells. There is still lack of evidence on long-term curative effect of this therapy, and further observation is required.

\section{References}

1. Mariotte E, Azoulay E, Galicier L, Rondeau E, Zouiti F, Boisseau P, Poullin P, de Maistre E, Provôt F, Delmas Y, et al; French Reference Center for Thrombotic Microangiopathies: Epidemiology and pathophysiology of adulthood-onset thrombotic microangiopathy with severe ADAMTS13 deficiency (thrombotic thrombocytopenic purpura): a cross-sectional analysis of the French national registry for thrombotic microangiopathy. Lancet Haematol 3: e237-e245, 2016.
2. Molica M, Massaro F, Annechini G, Baldacci E, D'Elia GM, Rosati R, Trisolini SM, Volpicelli P, Foà R and Capria S: Life-threatening autoimmune hemolytic anemia and idhiopatic thrombocytopenic purpura. Successful selective splenic artery embolization. Mediterr J Hematol Infect Dis 8: e2016020, 2016.

3. Taylor J, Rickey A, Johnson C, Connor C and Pullatt R: Management of a patient with refractory idiopathic thrombocytopenic purpura. Am Surg 82: 56-57, 2016.

4. Al-Mendalawi MD: Idiopathic thrombocytopenic purpura masquerading pediatric systemic lupus erythematosus. Indian J Dermatol 61: 236, 2016.

5. Huang WY, Sun QH and Chen YP: Expression and significance of $\mathrm{CD}^{+}{ }^{+} \mathrm{CD} 25^{+} \mathrm{CD} 127$ low regulatory T cells, TGF- $\beta$ and Notch 1 mRNA in patients with idiopathic thrombocytopenic purpura Zhongguo Shi Yan Xue Ye Xue Za Zhi 23: 1652-1656, 2015 (In Chinese).

6. Aboul-Fotoh L-M, Abdel Raheem MM, El-Deen MA and Osman AM: Role of $\mathrm{CD} 4^{+} \mathrm{CD} 25^{+} \mathrm{T}$ cells in children with idiopathic thrombocytopenic purpura. J Pediatr Hematol Oncol 33: 81-85, 2011.

7. Zhang QR, Wu DP, Chen LS and Cao RN: Curative effect of interleukin 11 on chronic idiopathic thrombocytopenic purpura. Zhongguo Shi Yan Xue Ye Xue Za Zhi 14: 176-178, 2006 (In Chinese).

8. Habe K, Wada H, Matsumoto T, Ohishi K, Ikejiri M, Matsubara K, Morioka T, Kamimoto Y, Ikeda T, Katayama N, et al: Presence of antiphospholipid antibodies as a risk factor for thrombotic events in patients with connective tissue diseases and idiopathic thrombocytopenic purpura. Intern Med 55: 589-595, 2016.

9. Vautier M, Georgin-Lavialle S, Hermine O, Bienvenu B Lacaze E, Gerard M and Aouba A: Efficiency and good tolerance of rituximab for idiopathic thrombocytopenic purpura revealing a $22 \mathrm{q} 11$ deletion syndrome. Rev Med Interne 8: 15-16, 2016 (In French).

10. McKiddie FI, Watson HG, Graham D, Phillips J and Staff RT: The impact of cell labelling technique on the retention of indium-labelled platelet imaging for idiopathic thrombocytopenic purpura. Nucl Med Commun 37: 215-216, 2016.

11. Smalisz-Skrzypczyk K, Romiszewski M, Matysiak M, Demkow U and Pawelec K: The influence of primary cytomegalovirus or Epstein-Barr virus infection on the course of idiopathic thrombocytopenic purpura. Adv Exp Med Biol 878: 83-88, 2016.

12. Park SH, Kim JY, Kim SK, Choe JY, Kim SG and Ryoo HM: Regulatory T-cells in systemic lupus erythematosus-associated thrombocytopenia: a comparison with idiopathic thrombocytopenic purpura. Lupus 24: e4, 2015.

13. Alam MM: Idiopathic thrombocytopenic purpura in children: a 10 years experience at tertiary care hospital. J Pak Med Assoc 64: $1358-1362,2014$

14. Kikuchi K, Miyakawa Y, Ikeda S, Sato Y and Takebayashi T: Cost-effectiveness of adding rituximab to splenectomy and romiplostim for treating steroid-resistant idiopathic thrombocytopenic purpura in adults. BMC Health Serv Res 15: 2, 2015.

15. Yao R, Lin Y, Li Q, Zhou X, Pan X, Bao Y, He M, Zhu B, Guo W, Lin X, et al: Downregulation of T-bet/GATA-3 ratio induced by IL-11 treatment is responsible for Th1/Th2 balance restoration in human immune thrombocytopenic purpura (ITP). J Thromb Thrombolysis 38: 183-189, 2014.

16. Abudureheman A, Yasen H, Fang Z, Xue Z, Jian-bing D, Xiu-min $\mathrm{M}$ and Xin-hong G: Expression of $\mathrm{CD} 4^{+} \mathrm{CD} 25^{+}$ regulatory $T$ cells and TGF- $\beta 1$ in patient with idiopathic thrombocytopenic purpura. Xi Bao Yu Fen Zi Mian Yi Xue Za Zhi 26: 895-897, 2010 (In Chinese).

17. Guo NH, Shi QZ, Hua JY, Li ZJ, Li J, He WF and Wu Q: Expression of regulatory T cells and Th17 cells in idiopathic thrombocytopenic purpura and its significance. Zhonghua Xue Ye Xue Za Zhi 31: 610-612, 2010 (In Chinese). 